\title{
Comparison of the effect of p65 siRNA and curcumin in promoting apoptosis in esophageal squamous cell carcinoma cells and in nude mice
}

\author{
FANG TIAN $^{1}$, CAIFENG ZHANG $^{2}$, WEIHONG TIAN $^{3}$, YANAN JIANG ${ }^{1}$ and XIAOYAN ZHANG $^{1}$ \\ ${ }^{1}$ Department of Pathophysiology, Basic Medical College, Zhengzhou University, Zhengzhou, Henan 450001; \\ ${ }^{2}$ Department of Digestion, the First Affiliated Hospital of Xinxiang Medical University, Weihui, Henan 453100; \\ ${ }^{3}$ Department of Gynecology Oncology, Anyang Tumor Hospital, Anyang, Henan 456150, P.R. China
}

Received January 31, 2012; Accepted March 5, 2012

DOI: $10.3892 /$ or.2012.1777

\begin{abstract}
The activation of the NF- $\kappa \mathrm{B}$ signaling pathway plays a critical role in carcinogenesis. The role of the NF- $\kappa \mathrm{B}$ pathway in esophageal squamous cell carcinoma (ESCC) remains illdefined. The objective was to detect whether p65siRNA and curcumin could promote ESCC cell apoptosis and increase the sensitivity of ESCC cells to chemotherapeutic drugs by inhibiting the NF- $\kappa \mathrm{B}$ signaling pathway, and to compared these two treatments. In the present study, the status of the NF- $\kappa \mathrm{B}$ pathway, in the two ESCC cell lines Eca109 and EC9706, was analyzed and the ability of p65 siRNA and curcumin alone or in combination with 5-FU to modulate this pathway in vitro and in vivo was investigated. The results showed that the $\mathrm{NF}-\kappa \mathrm{B}$ signaling pathway in the ESCC cell lines was constitutively activated. Both p65 siRNA and curcumin mediated suppression of activation of the NF- $\kappa$ B signaling pathway via inhibition of the expression of p65 or I $\kappa \mathrm{B} \alpha$ phosphorylation in ESCC cell lines. The cells treated with combination of p65 siRNA or curcumin and 5-FU revealed a lower cell viability and higher apoptosis compared to those treated with 5-FU alone. In a human ESCC xenograft model, p65 siRNA or curcumin and 5-FU alone reduced the tumor volume, respectively, but their combination had the strongest anticancer effects. Curcumin was more effective than p65 siRNA in vitro and in vivo. Overall, our results indicate that the constitutively activated $\mathrm{NF}-\kappa \mathrm{B}$ signaling pathway plays a crucial role in these two ESCC cell lines and both p65siRNA and curcumin can promote ESCC cell apoptosis and enhance the sensitivity to 5-FU through suppression of the $\mathrm{NF}-\kappa \mathrm{B}$ signaling pathway. It is still a long time before RNA interference will be used in the clinic. Therefore, curcumin is
\end{abstract}

Correspondence to: Dr Fang Tian, Pathophysiology, Basic Medical College, Zhengzhou University, 40 Daxue Road, Henan 450052, P.R. China

E-mail: tianfang715@yahoo.com.cn

Key words: esophageal squamous cell carcinoma, siRNA, curcumin, $\mathrm{NF}-\kappa \mathrm{B}$ signaling pathway, 5-Fluorouracil proved to be useful in the treatment of ESCC as it is a pharmacologically safe compound without side effects.

\section{Introduction}

Esophageal squamous cell carcinoma (ESCC) is one of the most frequently diagnosed cancers in developing countries, especially in Northern China (1). Furthermore, ESCC is one of the most aggressive cancers with poor prognosis and rapid progression (2) partly due to chemotherapeutic drugs. Although therapy strategies have improved, the prognosis of patients with ESCC is still poor. Moreover, ESCC is known to develop resistance to chemotherapeutic drugs, thus resulting in a dramatic decrease in the 5-year survival rate. 5-Fluorouracil (5-FU) is frequently used in combination chemotherapy for ESCC, but some patients show a poor response to 5-FU-based chemotherapy. In addition, toxicity was observed with doses required for efficiency, including myelosuppression, fever, nausea and vomiting. Thus, understanding the molecular mechanisms by which ESCC develops will allow us to design a new therapeutic strategy to improve the clinical outcome and tolerance to the disease.

Recently, accumulating evidence has demonstrated that nuclear factor- $\kappa \mathrm{B}(\mathrm{NF}-\kappa \mathrm{B} /$ Rel) plays an essential role in carcinogenesis. The most studied form is a heterodimer of the $\mathrm{p} 50$ and p65 subunits, predominant in many kinds of cells (3). A variety of extracellular stimulus factors, such as inflammatory cytokines, growth factors, DNA damaging agents, bacterial and viral products, trigger a common signal transduction pathway based on the phosphorylation, ubiquitination and proteasomedependent degradation of $\mathrm{I} \kappa \mathrm{B}$ to freely activated $\mathrm{NF}-\kappa \mathrm{B}$, which is then rapidly translocated to the nucleus and binds to the promoter region of the relevant downstream genes to evoke a series of transcriptional events (4). NF- $\kappa \mathrm{B}$ signaling pathway is mainly involved in cell growth, survival, differentiation and inhibition of apoptosis, thus making it a good target for cancer chemotherapy. Constitutive activation of $\mathrm{NF}-\kappa \mathrm{B}$ signaling pathway has been investigated in many human cancers, including hepatocellular, colonic, pancreatic and cervical cancers (5-8). Therefore, blocking the activity of this pathway could be used for prevention and treatment of malignancy. 
RNA interfere (RNAi) is a general mechanism for the sequence-specific gene-silencing induced by double stranded RNA (9). RNAi is mediated by small interfering RNA (siRNA), a double stranded form of RNA that is about 21-23 nucleotide long and is specific for the sequence of its target (10). Nowadays, RNAi has become a powerful strategy for knockdown and understanding gene function. Curcumin, an extract from the root of curcuma longa $L$, that is anti-oxidative and antiinflammatory, has been widely used in Indian medicine. More recently, curcumin has been used in cancer therapy alone or as a chemotherapy adjuvant. Numerous clinical trials have indicated that curcumin is quite safe when administered even at a daily dose of $12 \mathrm{~g}$ for 3 months (11).

We have used RNA interfere and curcumin respectively to study the role of NF- $\kappa \mathrm{B}$ signaling pathway in ESCC and the research showed that constitutive activation of $\mathrm{NF}-\kappa \mathrm{B}$ signaling pathway plays an important role in mediating proliferation and anti-apoptosis in ESCC (12-15). The purpose of the current study was to compare the inhibition efficiency of two methods in vitro and in vivo.

\section{Materials and methods}

Reagents. Curcumin was purchased from Sigma Company. Mouse monoclonal antibodies to p65 (sc-8008), p-IкB $\alpha$ (sc-8404) and IKK $\beta$ (sc-8014), rabbit polyclonal antibodies to $\mathrm{I} \kappa \mathrm{B} \alpha$ (sc-371) and p50 (sc-114) were purchased from Santa Cruz Biotechnology, Santa Cruz, USA). SignalSilence ${ }^{\circledR}$ NF- $\kappa$ B p65 siRNA (6261) was purchased from Cell Signaling Technology (USA). Annexin V-FITC kit was purchased from Beckman Coulter $^{\mathrm{TM}}$ (USA).

Cell culture. Two human ESCC cell lines, EC9706 and Eca109, were presented by State Key Laboratory of Molecular Oncology, Chinese Academy of Medical Science, cell lines were cultured in RPMI-1640 medium (Gibco-BRL) supplemented with $10 \%$ fetal bovine serum (Hyclone Laboratories, Logan, UT), $100 \mathrm{U} / \mathrm{ml}$ penicillin, and $100 \mu \mathrm{g} / \mathrm{ml}$ streptomycin at $37^{\circ} \mathrm{C}$ in $5 \% \mathrm{CO}_{2}$. Curcumin (Sigma, USA) was dissolved in dimethyl sulfoxide (DMSO) and prepared as $100 \mu \mathrm{M}$ solution (final concentration of DMSO in media, $0.1 \%$ ), then further diluted as needed in cell culture medium.

Immunocytochemical analysis. The immuno-reactivity was performed using SP kit according to the manufacturer's protocol. Briefly, the two cell lines were respectively plated on several glass slides and incubated at $37^{\circ} \mathrm{C}$ in $5 \% \mathrm{CO}_{2}$ for $24 \mathrm{~h}$. The slides were rinsed three times in phosphate buffered-saline (PBS, pH 7.4), fixed with 4\% formaldehyde at room temperature (RT) for $10 \mathrm{~min}$. After rinsing in PBS and treatment with 3\% $\mathrm{H}_{2} \mathrm{O}_{2}$ for $10 \mathrm{~min}$, the cells were blocked with $5 \%$ normal goat serum for $30 \mathrm{~min}$ in a humidified box at RT to eliminate nonspecific binding, and then incubated with anti-human p50, p65, $\mathrm{I} \kappa \mathrm{B} \alpha$, and $\mathrm{IKK} \beta$ antibodies (1:100), $\mathrm{p}-\mathrm{I} \kappa \mathrm{B} \alpha$ (1:50), as well as $\mathrm{PBS}$ as negative control, respectively, at $4^{\circ} \mathrm{C}$ overnight. After the slides were rinsed three times in PBS and incubated with counterpart second antibodies for $30 \mathrm{~min}$, they were developed with diaminobenzidine (DAB) under a light microscope to control the dyeing effect. Subsequently, photomicrography was carried out immediately under x400 magnification.
RNAi transfection. EC9706 (5x10 /well) and Eca109 $\left(6 \times 10^{4} /\right.$ well) cells were respectively grown in 6-well plates for $24 \mathrm{~h}$ in media without antibiotics before siRNA transfection. The cells were transfected for $5 \mathrm{~h}$ with $8 \mu \mathrm{l}$ of $10 \mu \mathrm{M}$ siRNA using $5 \mu \mathrm{l}$ transfection reagents. Subsequently, $0.8 \mathrm{ml}$ of normal growth medium containing serum and antibiotics was added to each well containing transfected cells without removing the transfection mixture. After the transfected cells were incubated for another $72 \mathrm{~h}$, they were harvested to test the expression of p65 proteins through western blotting (9). The results showed that the protein level of p65 decreased after transfection with p65 siRNA, while the protein level of MARK was not affected, suggesting that p65 siRNA can effectively downregulate the p65 protein level.

Preparation of cytoplasm and nuclear proteins. Cytoplasm and nuclear proteins were respectively extracted from the three cells about $90 \%$ confluence according to instructions of Nuclear and Cytoplasmic Extraction Reagents kit (Pierce Company). Aliquots of the proteins were stored at $-70^{\circ} \mathrm{C}$ and the protein concentrations were determined by Bradford protein-binding assay.

Western blot analysis. After transfection with p65 siRNA for $72 \mathrm{~h}$, the cells were harvested and expression of p65 protein in the cytoplasm was analyzed by western blot analysis using anti-p65 antibodies. The cells were treated with curcumin for various times (range: 0-60 min), and the cells extracted cytoplasm were analyzed by western blot analysis using anti$\mathrm{p}$-I $\mathrm{B} \alpha$. Briefly, Cytoplasm (50 $\mu \mathrm{g}$ ) from each cell line was added to $2 \mathrm{X}$ protein sample buffer, heated at $100^{\circ} \mathrm{C}$ for $5 \mathrm{~min}$, and separated with sodium dodecyl sulfate-polyacrylamide gels electrophoresis (SDS-PAGE), along with $20 \mu \mathrm{l}$ of pre-stained protein molecular weight marker (Fermentas no. SM0441) used as standards. According to the position indicated by pre-stained marker, the proteins were electrotransferred to supported nitrocellulose membranes (Hybond-c pure, Amersham) in transfer buffer containing $25 \mathrm{mM}$ Tris, $193 \mathrm{mM}$ glycine, and 20\% methanol. The membranes loading the proteins were treated with $5 \%$ skimmed milk in TBS-T (1X TBS, $0.05 \%$ Tween-20) at RT for $2 \mathrm{~h}$, and then rinsed three times in TBS-T and incubated with anti-p65, anti-p50, anti-I $\kappa \mathrm{B} \alpha$, anti-P-I $\kappa \mathrm{B} \alpha$ and anti-IKK $\beta$ antibodies diluted in $1 \%$ skimmed milk, respectively, at RT for $2 \mathrm{~h}$. The blots were rinsed three times in TBS-T and incubated with 1:5000 dilution of a goat anti-rabbit secondary antibody or a goat anti-mouse secondary antibody conjugated to horseradish peroxidase for $1 \mathrm{~h}$ at RT. After extensive washing with TBS-T, proteins were visualized on the membranes developed with DAB according to the manufacturer's instructions.

Annexin V-propidium iodide (PI) staining for apoptotic cells. ESCC cells or ESCC cells transfected with p65 siRNA alone or in combination with 5-FU and incubated for $48 \mathrm{~h}$. Or cells were seeded in 6-well plates and incubated overnight. Subsequently, cells were treated with $50 \mu \mathrm{M}$ curcumin in DMSO alone (final concentration of DMSO in media, $0.1 \%$ ) or in combination with 5-FU and incubated for $72 \mathrm{~h}$. These cells were harvested by rapid trypsinization, washed twice with PBS, and then the concentration of cells was adjusted to $1 \times 10^{5}$. The certain 
number cells were stained with fluorescein isothiocyanate (FITC)-Annexin V-PI according to the protocol summarized in the Annexin V-FITC kit (Beckman Coulter). Stained cells were placed on ice and protected from light for $10 \mathrm{~min}$ until they were evaluated by flow cytometry (BD FACSCalibur and Cell Quest 3.0). Viable cells are those that stain negatively for both Annexin V and PI. Cells in early apoptosis are positive for Annexin V and negative for PI, whereas those that are necrotic or in late apoptosis are positive for both Annexin V and PI.

Observation of the ESCC cell morphology. Morphological changes of ESCC cells were observed using microscope after treated with p65 siRNA, curcumin, 5-FU and p65 siRNA or curcumin plus 5-FU under a light microscope.

Animals and animal treatments. Male athymic BALB/c nude mice were purchased from Laboratory Animal Ltd in Shanghai, China. The animals, at 4-5 weeks of age, were housed five per cage in wire-top cages with sawdust bedding in an isolated, clean, air-conditioned room at a temperature of $25-26^{\circ} \mathrm{C}$ and a relative humidity of $\sim 50 \%$, lit $12 \mathrm{~h} /$ day. All animal studies were carried out in compliance with the Guide for the Care and Use of Laboratory Animals of Henan Province, China.

EC9706 cells were harvested from 70 to $80 \%$ confluent cultures by exposure to trypsinase and then washed, resuspended in PBS at $2 \times 10^{7}$ cells $/ \mathrm{ml}$. Only single-cell suspensions with $90 \%$ viability were used for injection. Cell resuspension $(200 \mu \mathrm{l})$ $\left(4 \times 10^{6}\right.$ cells) was inoculated s.c. into the right flank of athymic mice (16).

After 1 week of implantation, the tumors were measured in 3 dimensions, and the tumor volume was calculated according to the formula $\mathrm{V}=1 / 2 \mathrm{ab}^{2}$, where $\mathrm{a}$ and $\mathrm{b}$ represent the length and the width of tumor measured with sliding caliper, respectively. The animals were monitored for tumor growth every other day. When tumor size reached $100-200 \mathrm{~mm}^{3}$, tumorbearing animals were randomly assigned to the following 4 groups ( $\mathrm{n}=5$ ): (i) untreated control (PBS); (ii) p65 siRNA (50 $\mathrm{nM} /$ one animal) alone; (iii) curcumin (50 $\mu \mathrm{M} /$ one animal) alone ; (iv) 5-FU (10 mg/kg) alone; (v) p65 siRNA (50 nM/one animal) alone + 5-FU (10 mg/kg); (vi) curcumin $(50 \mu \mathrm{M} /$ one animal $)+5-\mathrm{FU}(10 \mathrm{mg} / \mathrm{kg})$. These treatments consisted of i.p. injections of p65siRNA or 5-FU administered every 3 days for 15 days. Animals of the p65 siRNA + 5-FU group were treated with p65 siRNA and 5-FU on alternative days. All procedures were conducted in a laminar-flow biosafety hood. Therapy was continued for 3 weeks, and then the mice of all groups were sacrificed. Tumor volumes were compared between the groups using unpaired Student's t-test. Inhibition rate $=[$ (tumor weight of control group - tumor weight of experimental group)/tumor weight of control group] $\times 100 \%$. The tumor tissue was immediately fixed in $4 \%$ buffered paraformaldehyde overnight for immunohistochemistry and TUNEL analysis.

Immunohistochemical analysis. Tissue sections of formalinfixed, paraffin-embedded specimens were deparaffinized in xylene, followed by treatment with a graded series of alcohol and distilled water, and washed thoroughly with PBS. Antigen retrieval for paraffin-embedded tissues was performed with sodium citrate $0.01 \mathrm{~mol} / 1$ ( $\mathrm{pH} \mathrm{6.0)}$, and then the container was placed in boiled water for $20 \mathrm{~min}$. Endogenous peroxidase was blocked by the use of $3 \%$ hydrogen peroxide in methanol for $10 \mathrm{~min}$. The sections were washed thrice with PBS and incubated for $30 \mathrm{~min}$ at RT with a protein-blocking solution (containing 10\% normal rabbit serum in PBS) in a chamber with saturated humidity. Excess blocking solution was drained, and the samples were incubated with different primary antibodies: mouse monoclonal antibodies to $\mathrm{p} 65, \mathrm{p}-\mathrm{I} \kappa \mathrm{B} \alpha$ (1:200 dilution; Santa Cruz Biotechnology), as well as PBS (negative control), respectively, at $4^{\circ} \mathrm{C}$ overnight. The samples were then rinsed thrice with PBS and subsequently incubated for 30 min with the appropriate dilution of the secondary antibody, followed by incubation with the HRP-linked streptavidin biotin complex in a box with saturated humidity for $10 \mathrm{~min}$ at RT. Positive reactions were visualized by incubating the slides with DAB for $5 \mathrm{~min}$. The sections were then washed thrice with PBS, counterstained with hematoxylin for $15 \mathrm{sec}$, dehydrated and cleared and mounted. Immunohistochemical evaluation was performed by a pathologist without knowledge of the clinical and pathological characteristics of these patients. Positive cells from five fields with $\mathrm{x} 400$ were examined and counted from each group.

Terminal deoxynucleotidyl transferase-mediated deoxyuridine triphosphate nick-end labeling (TUNEL) assay. DNA fragments of cells undergoing apoptosis were analyzed by the TUNEL method. Briefly, the tissue sections were deparaffinized in xylene, treated with a graded series of alcohol and distilled water, and washed thoroughly with PBS. The slides were incubated with proteinase $\mathrm{K}(20 \mu \mathrm{g} / \mathrm{ml}$ in PBS $)$ for $20 \mathrm{~min}$ at RT, and terminal deoxynucleotidyl transferase dUTP nick end-labeling (TUNEL) staining was carried out using the In Situ cell death detection kit (KeyGen Biotech Ltd., Nanjing, China) according to the manufacturer's instructions. TUNELpositive cells from 5 independent fields were counted manually.

Statistical analysis. The results of all experiments were performed by one-way analysis of variance (ANOVA), and the posthoc analysis for multiple was compared with LSD t-test using SPSS version 13.0 (SPSS, Chicago, IL, USA). Results are analyzed as means \pm standard deviation, $\mathrm{P}<0.05$ was considered as a significant difference.

\section{Results}

High expression of $N F-\kappa B$ signaling pathway in the cytoplasm of ESCC cell lines. The two ESCC cell lines had intense immunoreactivity of p50, p65, I $\kappa \mathrm{B} \alpha$ and $\mathrm{p}-\mathrm{I} \kappa \mathrm{B} \alpha, \operatorname{IKK} \beta$ in the cytoplasm by immunocytochemistry (Fig. 1A). Western blot analysis of cytoplasmic extracts from the ESCC cell lines showed that the two ESCC cell lines had the highest expression of $\mathrm{p} 50, \mathrm{p} 65, \mathrm{I} \kappa \mathrm{B} \alpha$ and $\mathrm{p}-\mathrm{I} \kappa \mathrm{B} \alpha, \mathrm{IKK} \beta$ in the cytoplasm (Fig. 1B).

Constitutive activation of $N F-\kappa B$ signaling pathway in ESCC is inhibited by 655 siRNA and curcumin in vitro. After transfected with p65 siRNA for $72 \mathrm{~h}$, the cells were harvested and p65 protein expression in the cytoplasm was analyzed by western blot analysis. As shown in Fig. 2A, the protein level of p65 decreased after transfected with p65 siRNA, while the protein level of MARK was not affected, suggesting that p65 siRNA can effectively inhibit p65 protein levels. Phosphorylation of I $\mathrm{B} \alpha$ is necessary for its degradation and the subsequent activation 


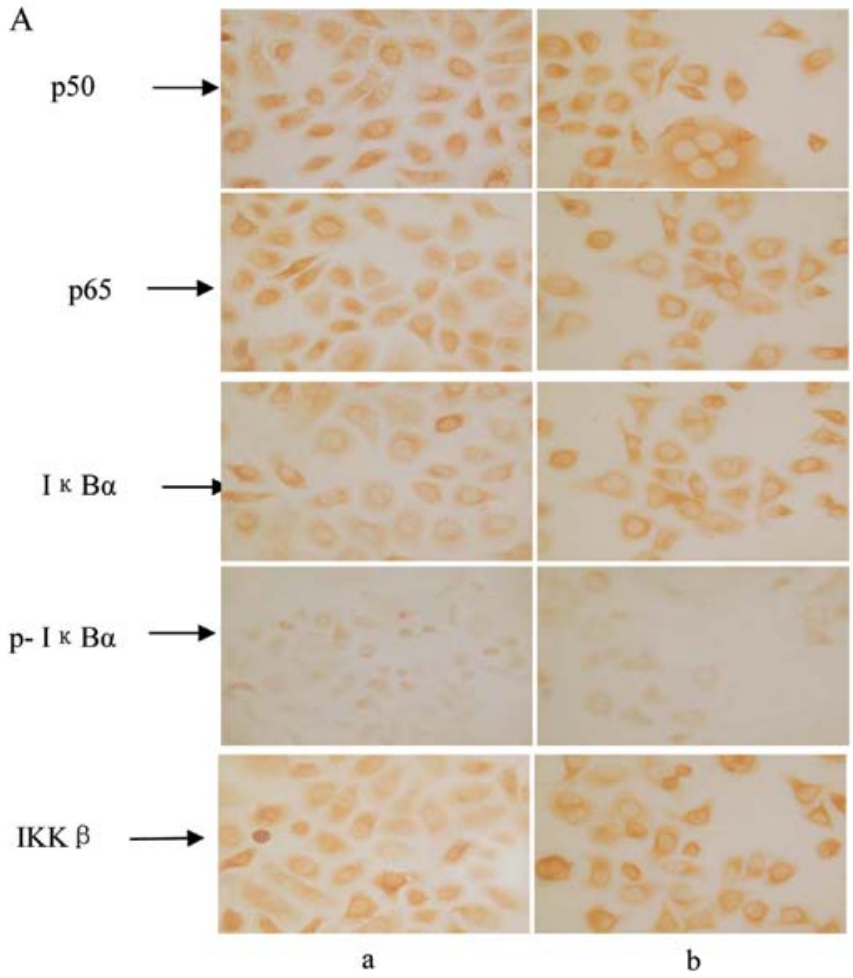

B

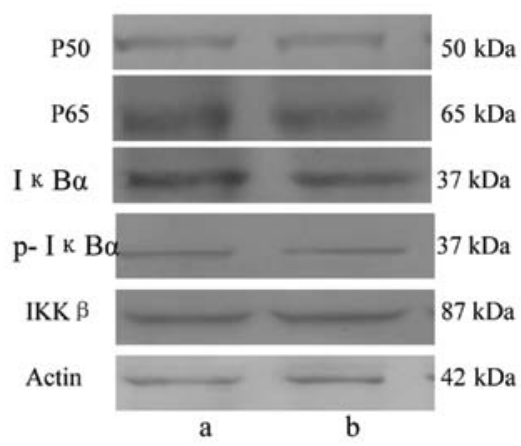

Figure 1. NF- $\mathrm{kB}$ signaling pathway is activated in cell lines. (A). Immunocytochemiscal expression and localization of p50, p65, IкB $\alpha$, $\mathrm{p}$-IкB $\alpha$ and IKK $\beta$ in EC9706 and Eca109. (B). Western blot analysis was

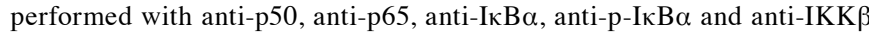
antibodies. Lane a, EC9706; Lane b, Eca109. Equal protein loading was controlled with anti-actin antibody.

of NF- $\mathrm{KB}$ signaling pathway. The results of western blotting indicated that curcumin inhibited I $\kappa \mathrm{B} \alpha$ phosphorylation and degradation in the two ESCC cell lines after treatment with $50 \mu \mathrm{M}$ curcumin at the different time points $(0-60 \mathrm{~min})$. As loading controls in these tests the anti-actin antibody was used (Fig. 2B) (13,15).

Comparison the effect between p65 siRNA and curcumin in inducing apoptosis in ESCC cells. To investigate whether suppression of NF- $\mathrm{kB}$ signaling pathway evokes cell apoptosis of ESCC cells, two ESCC cell types were treated with p65 siRNA and curcumin alone or in combination with 5-FU for $72 \mathrm{~h}$ and analyzed by Annexin V/PI staining. The results showed that incubation with p65 siRNA and curcumin alone $(50 \mu \mathrm{M})$, the percentage of apoptotic cells in EC9706 and
A

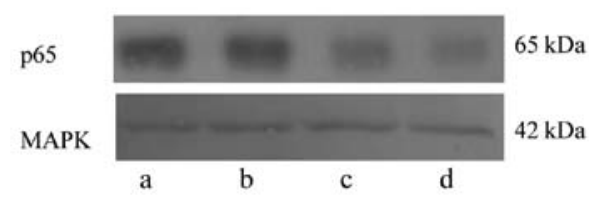

B

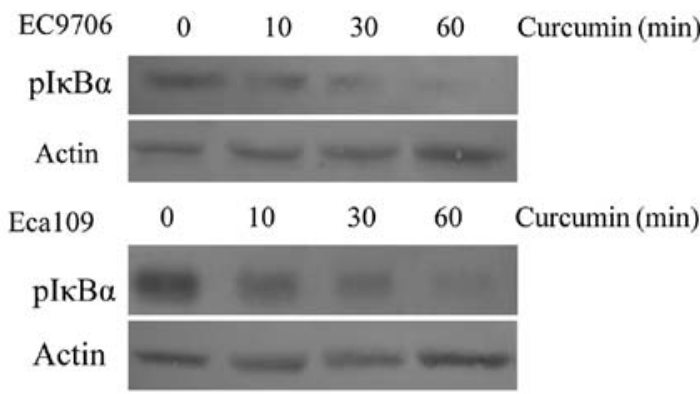

Figure 2. Constitutve activation of NF-kB signaling pathway in ESCC was inhibited by p65 siRNA and curcumin. (A) Suppression of expression of p65 subunit of NF-кB by siRNA targeting the p65 in the ESCC cell lines. The cells were transfected with or without siRNA for $72 \mathrm{~h}$. Lane a, EC9706; lane b, Eca109; lane c, EC9706 transfected with siRNA; lane d, Eca109 transfected with siRNA. (B) ESCC cells were treated with curcumin $(50 \mu \mathrm{M})$ for different times, and cytoplasm protein extracts ( $50 \mu \mathrm{g} / \mathrm{lane}$ ) were subjected to electrophoresis on $12 \%$ SDS-polyacrylamide gels and were performed with anti-pI $\kappa \mathrm{B} \alpha$ antibody. Proteins were visualized with DAB staining. Equal protein loading was controlled with anti-actin antibody.

Table I. The apoptosis percentage of EC9706, Eca109 detected by flow cytometry (means $\pm \mathrm{SD}, \mathrm{n}=3$ ).

\begin{tabular}{lcr}
\hline Group & EC9706 $(\%)$ & Eca109 $(\%)$ \\
\hline Control group & $2.03 \pm 0.08$ & $2.66 \pm 0.25$ \\
siRNA group & $6.65 \pm 0.27$ & $8.03 \pm 0.06$ \\
Curcumin & $10.8 \pm 0.59^{\mathrm{a}}$ & $16.0 \pm 0.1^{\mathrm{a}}$ \\
siRNA+5-FU & $24.61 \pm 0.85$ & $28.87 \pm 0.35$ \\
Curcumin+5-FU & $27.01 \pm 0.33^{\mathrm{b}}$ & $32.45 \pm 0.5^{\mathrm{b}}$ \\
\hline
\end{tabular}

${ }^{\mathrm{a}} \mathrm{P}<0.05$ vs. siRNA group; ${ }^{\text {b }}<0.05$ vs. siRNA $+5-\mathrm{FU}$.

Eca109 was higher than that in the control group; incubation with p65 siRNA and curcumin plus 5-FU (327 $\mu \mathrm{g} / \mathrm{ml})$, the percentage of apoptotic cells and death cells in EC9706 and Eca109 was significantly increased, indicating that p65 siRNA and curcumin enhanced the sensitivity of the ESCC cells to 5-FU (Table I, $\mathrm{P}<0.05$ ). Curcumin in combination with 5-FU had the strongest anticancer effect as compared with the other groups (Table I, $\mathrm{P}<0.05$ ).

The change of morphology in the ESCC cells after treatment with p65 siRNA and curcumin alone or combined with 5-FU. After incubated with p65 siRNA and curcumin for $72 \mathrm{~h}$, the changes of morphology of the two ESCC cells included cell 


\section{EC9706}
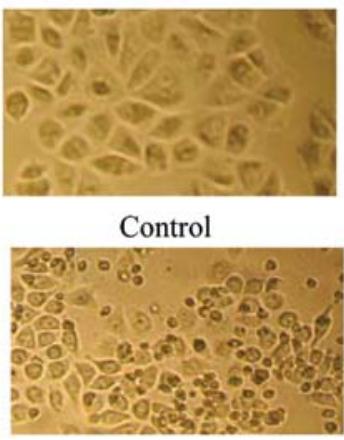

$5-\mathrm{FU}$

Ecal09

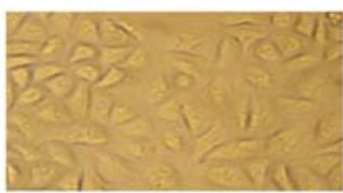

Control

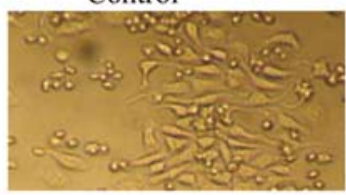

$5-\mathrm{FU}$

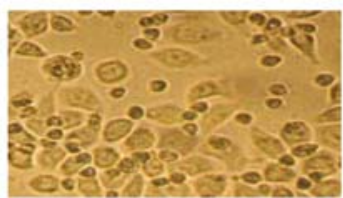

Curcumin

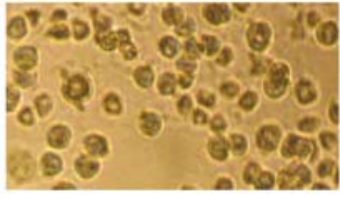

Curcumin $+5-\mathrm{FU}$

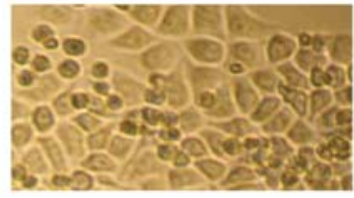

siRNA

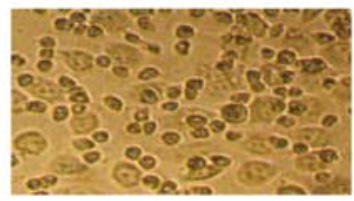

siRNA +5-FU

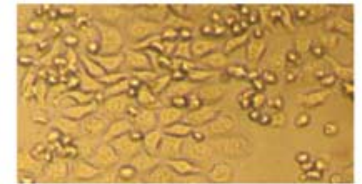

Curcumin

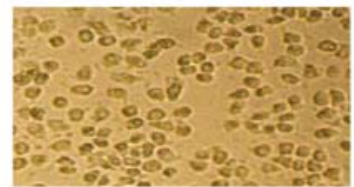

Curcumin $+5-\mathrm{FU}$
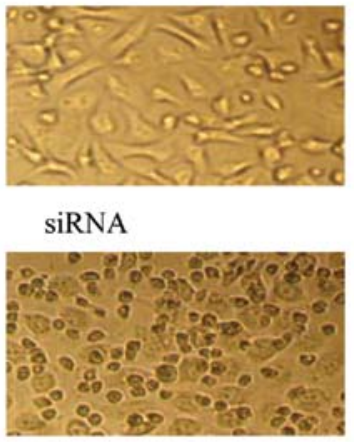

siRNA+5-FU

Figure 3. The changes of morphology of EC9706 and Eca109 cells were observed using a microscope after treatment with p65 siRNA and curcumin alone or in combination with 5-FU (x400). In normal culture condition, 60-70\% confluent ESCC cells were divided into six groups and then incubated with PRIM-1640, curcumin, siRNA, 5-FU, curcumin plus 5-FU or siRNA plus 5-FU for $72 \mathrm{~h}$.

Table II. Comparisons of mouse weight and tumor volume in different treatment groups $(\mathrm{n}=5)$.

\begin{tabular}{lccc}
\hline Group & Animal weight $(\mathrm{g})$ & $\begin{array}{c}\text { Tumor volume } \\
\text { before therapy }\left(\mathrm{mm}^{3}\right)\end{array}$ & $\begin{array}{c}\text { Tumor volume } \\
\text { after therapy }\left(\mathrm{mm}^{3}\right)\end{array}$ \\
\hline Control & $21.13 \pm 1.46$ & $147.09 \pm 40.77$ & $1703.25 \pm 491.18$ \\
5-FU & $20.70 \pm 1.17$ & $152.38 \pm 45.36$ & $986.50 \pm 210.59$ \\
p65 siRNA & $21.12 \pm 1.51$ & $145.12 \pm 42.45$ & $1322.25 \pm 256.50$ \\
Curcumn & $20.25 \pm 1.68$ & $154.66 \pm 47.23$ & $1306.25 \pm 228.41$ \\
p65 siRNA + 5-FU & $20.23 \pm 1.54$ & $152.97 \pm 41.68$ & $797.01 \pm 147.05^{\mathrm{a}}$ \\
Curcumin + 5-FU & $21.22 \pm 1.44$ & $149.56 \pm 40.12$ & $604.75 \pm 159.59^{\mathrm{a}, \mathrm{b}}$ \\
\hline
\end{tabular}

${ }^{\mathrm{a} C}$ Compared with 5-FU group, $\mathrm{P}<0.05$; ${ }^{\mathrm{b}}$ Compared with $\mathrm{p} 65$ siRNA +5 -FU group, $\mathrm{P}<0.05$.

shrinkage, cell proliferation inhibition and increase of the suspension dead cells. When incubated with p65 siRNA and curcumin plus 5-FU for $72 \mathrm{~h}$, the changes were more visibly and the apoptotic cells were obviously increased (Fig. 3).

p65 siRNA and curcumin potentiates the antitumor effects of 5-FU in ESCCXenografts. Due to the abnormally high activity of the NF- $\kappa B$ signaling pathway in ESCC cell lines, the effect of p65 siRNA and curcumin alone or in combination with 5-FU on the growth of ESCC xenograft was evaluated in the transplantable tumors of EC9706. These tumor-bearing mice were randomized into six groups, and therapy was initiated on day 7 after tumor implantation on the basis that the groups showed no difference in tumor volume $(\mathrm{P}>0.05)$. The tumor volume in the control group was greater than in the other three treated groups. All animals were sacrificed on day 28 , and the final tumor volume was significantly decreased in the $\mathrm{p} 65$ siRNA + 5-FU group and curcumin + 5-FU group as compared with 5-FU alone $(\mathrm{P}<0.05)$. Also, the tumor volume in the p65 siRNA, curcumin or 5-FU alone group was signifi- 


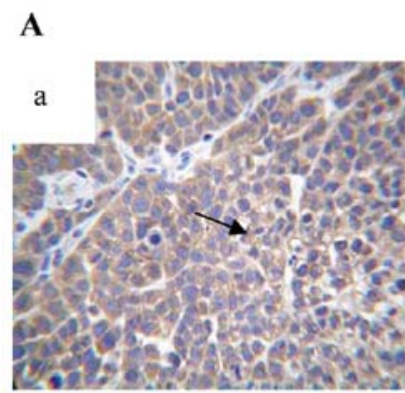

$375 \pm 39$

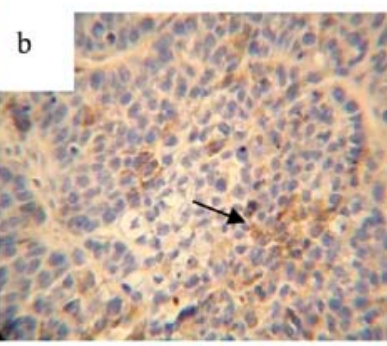

$92 \pm 17$

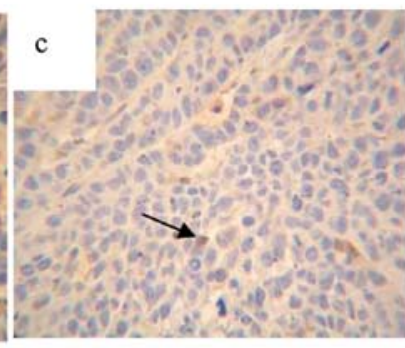

$87 \pm 12$

\section{B}

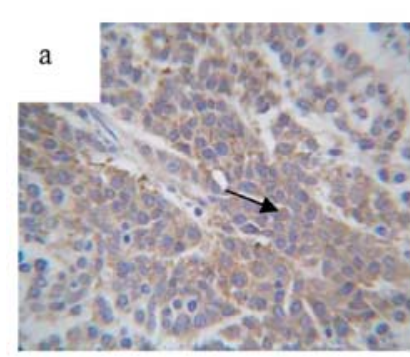

$324 \pm 32$

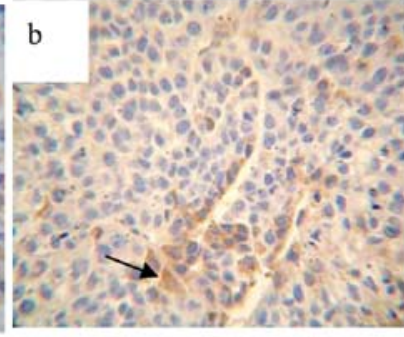

$97 \pm 15$

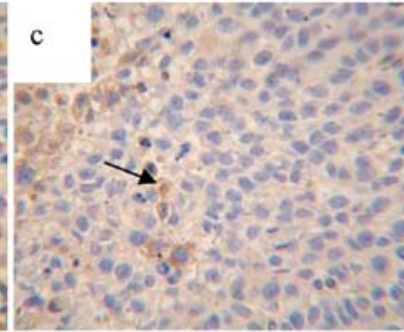

$81 \pm 14$

Figure 4. (A) Expression of p65 was inhibited in tumor tissues after treatment with p65 siRNA and p65 siRNA + 5-FU. Immunohistochemistry analysis in tumor tissue from EC9706 xenografts of the groups with different treatments. (a) Positive control (n=5, x400). (b) p65 siRNA group (n=5, x400). (c) p65 siRNA+5-FU group $(n=5, x 400)$. (B) Expression of $\mathrm{pI} \kappa \mathrm{B} \alpha$ was inhibited in tumor tissues after being treated with curcumin in curcumin group or in curcumin

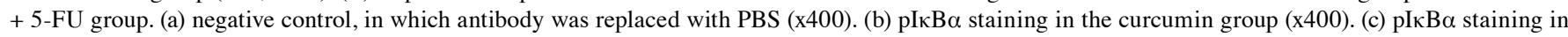
the curcumin +5 -FU group $(\mathrm{x} 400)$.

Table III. Comparison of average tumor weight and inhibition rate in the differently treated groups $(n=5)$.

\begin{tabular}{llc}
\hline Group & $\begin{array}{c}\text { Tumor weight } \\
(\mathrm{g})\end{array}$ & $\begin{array}{c}\text { Inhibition rate } \\
\text { of tumor }(\%)\end{array}$ \\
\hline Control & $1.15 \pm 0.59$ & \\
5-FU & $0.63 \pm 0.15$ & 45.22 \\
p65 siRNA & $0.85 \pm 0.26^{\mathrm{a}}$ & 26.10 \\
Curcumin & $0.76 \pm 0.23^{\mathrm{a}, \mathrm{b}}$ & 34.78 \\
p65 siRNA + 5-FU & $0.47 \pm 0.13^{\mathrm{a}}$ & 62.61 \\
Curcumin + 5-FU & $0.32 \pm 0.17^{\mathrm{a}, \mathrm{c}}$ & 83.48 \\
\hline
\end{tabular}

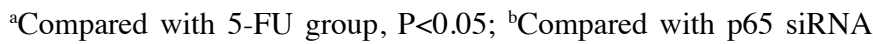
group, $\mathrm{P}>0.05$; ${ }^{\mathrm{c}}$ Compared with $\mathrm{p} 65$ siRNA+5-FU group, $\mathrm{P}<0.05$.

cantly decreased as compared with the control group $(\mathrm{P}<0.05)$ (Table II).

Additionally, control groups showed consistently larger tumors than the treated groups $(\mathrm{P}<0.05)$ through comparison of dissected tumor weight. The p65 siRNA + 5-FU group and curcumin $+5-\mathrm{FU}$ group showed a remarkable inhibition of tumor growth. The inhibition rates of p65 siRNA, curcumin, 5-FU, p65 siRNA + 5-FU and curcumin + 5-FU groups were $26.10,34.75,45.22,62.61$ and $83.48 \%$, respectively, when the treatments were terminated (Table III). Obviously, p65 siRNA and curcumin in combination with 5-FU had the strongest anticancer effect as compared with the other groups. While curcumin was more effective than p65 siRNA.

Constitutive activation of NF- $\kappa B$ signaling pathway in ESCC was inhibited by p65 siRNA and curcumin in vivo. To determine the p65 status in these tumors, the expression of p65 in the xenografts was detected by immunohistochemistry. As shown in Fig. 4A, p65 was mainly expressed in the cell cytoplasm, and positivity for p65 was 375,92 and 87 cells/1500 cells in the control, p65 siRNA and p65 siRNA + 5-FU groups, respectively, with a significant difference when the p65 siRNA or p65 siRNA + 5-FU group was compared with the control group $(\mathrm{P}<0.05)(14)$.

To explore whether the anticancer effect of curcumin in vivo was also achieved via inhibition of NF- $\mathrm{kB}$ signaling pathway, the phosphorylation status of I $\mathrm{B} \alpha$ in the xenograft were detected by immunohistochemistry. As indicated in Fig. 4B, pI $\mathrm{B} \alpha \alpha$ was expressed in the cell cytoplasm. Positive cell expression of pI $\mathrm{B} \alpha$ was counted in 1500 cells in random fields per tumor tissue from nude mice and then analyzed by one-way ANOVA. The positive cell numbers of expression of $\mathrm{pI \kappa B} \alpha$ were decreased in groups treated with curcumin alone of combined with 5-FU compared to that of control group $(\mathrm{P}<0.05)(15)$.

p65 siRNA and curcumin induces cell apoptosis in the tumor tissues. The antitumor effects of p65 siRNA and curcumin on ESCC xenografts were detected in an in vivo model. TUNEL staining showed that there were 4, 40, 79 and 87 apoptotic cells/1500 cells in the control groups, 5 -FU, p65 siRNA+ 5-FU 
Table IV. Detection of TUNEL in tumor tissues of control and treated mice.

\begin{tabular}{lcc}
\hline Group & $\begin{array}{c}\text { Cell } \\
\text { numbers/slide }\end{array}$ & $\begin{array}{c}\text { Positive cell } \\
\text { numbers/slide }\end{array}$ \\
\hline Control & 1500 & $4 \pm 1$ \\
5-FU & 1500 & $40 \pm 11$ \\
p65 siRNA + 5-FU & 1500 & $79 \pm 13^{\mathrm{a}}$ \\
Curcumin + 5-FU & 1500 & $87 \pm 16^{\mathrm{a}}$ \\
\hline
\end{tabular}

${ }^{\mathrm{a} C}$ Compared with control and 5-FU group, $\mathrm{P}<0.05$.

and curcumin +5 -FU, respectively. There was a significant difference between each of the treated groups and the control group $(\mathrm{P}<0.05)$. The apoptotic rate in the p65 siRNA + 5 -FU and curcumin +5 -FU groups were higher than that in the 5-FU alone group $(\mathrm{P}<0.05)$, indicating p65 siRNA and curcumin is highly effective in potentiating apoptosis effects of 5-FU (Table IV).

\section{Discussion}

There is some evidence suggesting that environmental factors such as hot beverages, dystrophy, smoking and alcohol intake affect the risk of developing esophageal cancer. Therefore, environmental and life-style aspects are major contributors to human carcinogenesis and many human cancers may be preventable. Research should pay attention to prevention as well as detection and treatment of cancer. Thus, the elucidation of molecular and cellular targets critical in cancer development and prevention is an area of intensive research and is driving the development of highly specific small-molecule inhibitors, which may either prevent carcinogenesis, curtail its progression, or even cure the disease. The activation of the mitogen-activated protein kinase cascades can result in a multitude of cellular responses, including apoptosis, proliferation, inflammation, differentiation, and development, which are mediated through the transcription factors AP-1 and nuclear factor $\kappa \mathrm{B}(17)$.

Research has revealed that NF- $\mathrm{KB}$ is an important regulator for several genes involved in cell survival, transformation, differentiation, invasion and growth of the cancer cells (18-20). NF- $\mathrm{KB}$ activation is also related to chemoresistance (21). 5-FU has been extensively used as the front-line chemotherapeutic agent in esophageal cancers. One of the molecular mechanisms involved in 5-FU-induced apoptosis in cancer cells is due to the suppression of NF- $\mathrm{kB}$ activity (22). Tamatani et al also showed that inhibition of NF- $\mathrm{KB}$ signaling pathway in human oral cancer, as a rational approach, would improve conventional radiotherapy and chemotherapy outcomes (23). Many other studies using different inhibitors affecting the activated IKK/NF- $\mathrm{BB}$ signaling pathway have demonstrated that these methods have beneficial effects on tumor transformation or increase the sensitivity to radio- and chemotherapy $(24,25)$.

For siRNA to be a useful tool in gene knockdown experiments and ultimately for therapeutic purposes, siRNA- mediated transcriptional silencing must be specific. Many studies (26-28) have shown that siRNA-mediated gene silencing can be a reliable and valuable approach for largescale screening of gene function and drug-target identification and validation. Our study showed that the signaling pathway of NF- $\kappa \mathrm{B}$ was activated in two ESCC cell lines, the expression of p65 was efficiently inhibited after transfection with p65 siRNA and then suppressed its DNA binding activity. Downregulation of p65 efficiently suppressed EC9706 and Eca109 cell growth in a time-dependent manner and enhanced the sensitivity of these cells to 5-FU in vitro; Both p65 siRNA and 5-FU induced obvious tumor repression, especially when they were combined. The overall apoptosis in tumor tissue, as indicated by TUNEL staining, was synergistically upregulated by p65 siRNA combined with 5-FU (12-15). Together, these studies support the idea that p65 siRNA is a useful tool to study the role of NF- $\mathrm{kB}$ signaling pathway in the carcinogenesis of ESCC.

Diet has attracted a great deal of interest in cancer prevention because it has been suggested to play a major role in cancer risk (29). In addition to being professed as generally safe, some dietary factors appear to have efficacy as anticancer agents by preventing or reversing premalignant lesions, as well as by reducing the risk of developing a second primary tumor (30). Some evidence suggests that certain dietary components might be used in combination with traditional chemotherapeutic agents to treat cancer (31).

Curcumin is an extract from the root of curcuma longa $L$, with anti-oxidative and anti-inflammatory properties, and has been widely used in Indian medicine. More recently, curcumin has also been used in cancer therapy as a drug or as an adjuvant to general chemotherapy, for example, some studies have revealed that curcumin inhibits cell proliferation and induces apoptosis in human leukemia, prostate cancer, and non-small cell lung cancer cell lines (32-34). Our previous study showed that curcumin mediated inhibition of NF- $\kappa B$ was regulated via inhibition of IкB $\alpha$ phosphorylation, suppression of NF- $\mathrm{kB}-\mathrm{DNA}$ binding activity, and downregulation of Bcl-2 and CyclinD1 expressions in ESCC cell lines. The cells treated with combination of curcumin and 5-FU revealed lower cell viability and higher apoptosis than those treated with 5-FU alone in vitro and in vivo (12-15).

Comparison of p65 siRNA with curcumin in vitro and in vivo, the results identified that both p65 siRNA and curcumin could inhibit the activation of NF- $\kappa \mathrm{B}$ signaling pathway in ESCC through suppressing different signaling targets. Specifically p65 siRNA, is a useful tool to study gene function. The results showed that constitutively activated NF- $\kappa \mathrm{B}$ signaling pathway plays an important role in carcinogenesis of ESCC. While comparison of the effect between $\mathrm{p} 65$ siRNA and curcumin, showed some differences. In vitro, in p65 siRNA and curcumin plus 5-FU (327 $\mu \mathrm{g} / \mathrm{ml})$, the percentage of apoptotic cells and dead cells in EC9706 and Eca109 was significantly increased, and curcumin in combination with 5-FU had the strongest anticancer effect as compared with the p65 siRNA + 5-FU group. In vivo, the tumor volume in the p65 siRNA + 5-FU group was greater than in the curcumin + 5-FU group and the inhibition rates of p65 siRNA + 5-FU and curcumin + 5-FU groups were 62.61 and $83.48 \%$, respectively, when the treatments were termi- 
nated. Clearly, curcumin +5 -FU had the strongest anticancer effect as compared with the p65 siRNA + 5-FU. However, the result of TUNEL indicated that p65 siRNA and curcumin had the same efficacy in potentiating the apoptosis effects of 5-FU.

Therefore, p65 siRNA should be analyzed to better define the role of RNAi as a scientific tool in human ESCC. However, the technology of RNAi has significant shortcoming with short acting time, which greatly limits its clinical use. While cucumin has minimal systemic side effects, and thus makes it a likely candidate for clinical use, alone or combined with other agents (35). Curcumin is in clinical trial at M.D. Anderson, TX, USA for the treatment of pancreatic cancer (36) and multiple myeloma (37). It has been found to be highly safe and well tolerated even at very high doses (38).

Taken together, the present study demonstrates that constitutively activated $\mathrm{NF}-\kappa \mathrm{B}$ signaling pathway exists in the ESCC, which may be an important mechanism responsible for survival and proliferation of the ESCC cells. Curcumin, alone or in combination with 5-FU, can be used as an adjuvant agent and enhance the sensitivity of anticancer agents in the treatment of this cancer. Therefore, suppression of NF- $\kappa \mathrm{B}$ signaling pathway may be a potential target for the therapeutic strategies in ESCC with high $\mathrm{NF}-\kappa \mathrm{B}$ activity and curcumin shows potential to be an important chemoprevention drug of this cancer.

\section{Acknowledgements}

This study was supported by a grant from the '211 Project' of the 10th Five-Year Plan (Education Ministry of China, 2002-2) and Henan Medical Science and Technique Foundation (200803005) and University Key Teacher by the Henan Educational Committee (2011GGJS-010).

\section{References}

1. Pisani P, Parkin DM, Bray F and Ferlay J: Estimates of the worldwide mortality from 25 cancers in 1990. Int J Cancer 83: 18-29, 1999.

2. Montesano R, Hollstein M and Hainaut P: Genetic alterations in esophageal cancer and their relevance to etiology and pathogenesis: a review. Int J Cancer 69: 225-235, 1996.

3. Chen FE and Ghosh G: Regulation of DNA binding by Rel/ NF-kappaB transcription factors: structural views. Oncogene 18: 6845-6852, 1999.

4. Pahl HL: Activators and target genes of Rel/NF- $\mathrm{kB}$ transcription factors. Oncogene 18: 6853-6866, 1999.

5. Guo K, Kang NX, Li Y, Sun L, Gan L, Cui FJ, Gao MD and Liu KY: Regulation of HSP27 on NF-kappaB pathway activation may be involved in metastatic hepatocellular carcinoma cells apoptosis. BMC Cancer 9: 100-110, 2009.

6. Yu HG, Yu LL, Yang Y, Luo HS, Yu JP, Meier JJ, Schrader H, Bastian A, Schmidt WE and Schmitz F: Increased expression of RelA/nuclear factor-kappa B protein correlates with colorectal tumorigenesis. Oncology 65: 37-45, 2003.

7. Liptay S, Weber CK, Ludwig L, Wagner M, Adler G and Schmid RM: Mitogenic and antiapoptotic role of constitutive $\mathrm{NF}-\kappa \mathrm{B} / \mathrm{Rel}$ activity in pancreatic cancer. Int J Cancer 105: 735-746, 2003.

8. Nair A, Venkatraman M, Maliekal TT, Nair B and Karimagaram D: $\mathrm{NF}-\kappa \mathrm{B}$ is constitutively activated in high-grade squamous intraepithelial lesions and squamous cell carcinomas of the human uterine cervix. Oncogene 22: 50-58, 2003

9. Hannon GJ: RNA interference. Nature 418: 244-251, 2002.

10. Tuschl T and Borkhardt A: Small interfering RNAs: a revolutionary tool for the analysis of gene function and gene therapy. Mol Interv 2: 158-167, 2002.
11. Goel A, Kunnumakkara AB and Aggarwal BB: Curcumin as 'Curecumin': from kitchen to clinic. Biochem Pharmacol 75: 787-809, 2008.

12. Tian F, Song M, Xu PR, Liu HT and Xue LX: Effect of siRNAmediated inhibition of nuclear factor- $\kappa \mathrm{B}$ in combination with 5-FU on apoptosis of squamous cell carcinoma cell lines. Shi Jie Hua Ren Xiao Hua Za Zhi 16: 1716-1721, 2008.

13. Tian F, Song M, Xu PR, Liu HT and Xue LX: Curcumin promotes apoptosis of esophageal squamous carcinoma cell lines through inhibition of NF- $\mathrm{KB}$ signaling pathway. Chin J Cancer 27: 566-570, 2008 (In Chinese).

14. Tian F, Fan TL, Jiang YN, Zhang XY and Wang XH: A small interfering RNA targeting NF- $\kappa \mathrm{B}$ p65 alone or combined with 5-FU inhibits growth of esophageal squamous cell carcinoma in nude mice. Pathol Res Pract 208: 32-38, 2012.

15. Tian F, Zang WD, Xu PR, Liu HT and Xue LX: Nuclear factorkappaB signaling pathway constitutively activated in esophageal squamous cell carcinoma cell lines and inhibition of growth of cells by siRNA. Acta Biochim Biophys Sin 38: 318-326, 2006.

16. Hou GQ, Zhang Q, Wang L, Liu M, Wang J and Xue LX: mTOR inhibitor rapamycin alone or combined with cisplatin inhibits growth of esophageal squamous cell carcinoma in nude mice. Cancer Lett 290: 248-254, 2010.

17. Bode AM and Dong Z: Signal transduction molecules as targets for cancer prevention. Sci Signal 2: mr2, 2009.

18. Prasad S, Ravindran J and Aggarwal BB: NF-kappaB and cancer: how intimate is this relationship. Mol Cell Biochem 336: 25-37, 2010.

19. Sethi G, Ahn KS, Sung B and Aggarwal BB: Pinitol targets nuclear factor-kappaB activation pathway leading to inhibition of gene products associated with proliferation, apoptosis, invasion, and angiogenesis. Mol Cancer Ther 7: 1604-1614, 2008.

20. Sung B, Pandey MK and Aggarwal BB: Fisetin, an inhibitor of cyclin-dependent kinase 6, down-regulates nuclear factor-kappaB-regulated cell proliferation, antiapoptotic and metastatic gene products through the suppression of TAK-1 and receptor-interacting protein-regulated IkappaBalpha kinase activation. Mol Pharmacol 71: 1703-1714, 2007.

21. Sethi G, Sung B and Aggarwal BB: Nuclear factor $-\kappa B$ activation: from bench to bedside. Exp Biol Med 233: 21-31, 2008.

22. Aota K, Azuma M, Yamashita T, Tamatani T, Motegi K, Ishimaru N, Hayashi $\mathrm{Y}$ and Sato M: 5-Fluorouracil induced apoptosis through the suppression of NF- $\kappa \mathrm{B}$ activity in human salivary gland cancer cells. Biochem Biophys Res Commun 273: 1168-1174, 2000.

23. Tamatani T, Azuma M, Ashida Y, Motegi K, Takashima R, Harada K, Kawaguchi S and Sato M: Enhanced radiosensitization and chemosensitization in NF- $\mathrm{KB}$-suppressed human oral cancer cells via the inhibition of $\gamma$-irradiation- and 5-FU-induced production of IL-6 and IL-8. Int J Cancer 108: 912-921, 2004.

24. Duffey DC, Chen ZH, Dong G, Ondrey FG, Wolf JS, Brown K, Siebenlist $U$ and Van WC: Expression of a dominant-negative mutant inhibitor- $\kappa \mathrm{B}$ of nuclear factor- $\kappa \mathrm{B}$ in human head and neck squamous cell carcinoma inhibits survival, proinflammatory cytokine expression, and tumor growth in vivo. Cancer Res 59: 3468-3475, 1999

25. Zhou M, Gu LB, Zhu NX, Woods WG and Findley HW: Transfection of a dominant-negative mutant NF- $\kappa \mathrm{B}$ inhibitor $(\mathrm{I} \kappa \mathrm{B} \alpha)$ represses p53-dependent apoptosis in acute lymphoblastic leukemia cells: interaction of I $\mathrm{B} \alpha$ and p53. Oncogene 22: 81378144,2003

26. Chi JT, Chang HY, Wang NN, Chang DS, Dunphy N and Brown PO: Genomewide view of gene silencing by small interfering RNAs. Proc Natl Acad Sci USA 100: 6343-6346, 2003.

27. Semizarov D, Frost L, Sarthy A, Kroeger P, Halbert DN and Fesik SW: Specificity of short interfering RNA determined through gene expression signatures. Proc Natl Acad Sci USA 11: 6347-6352, 2003.

28. Jackson AL, Bartz SR, Schelter J, Kobayashi SV, Burchard J, Mao M, Li B, Cavet G and Linsley PS: Expression profiling revealsoff-target gene regulation by RNAi. Nat Biotechnol 21: 635-637, 2003.

29. McMichael AJ: Food, nutrition, physical activity and cancer prevention. Authoritative report from World Cancer Research Fund provides global update. Public Health Nutr 11: 762-763, 2008.

30. Hong WK: General keynote: The impact of cancer chemoprevention. Gynecol Oncol 88: S56-S58, 2003. 
31. Ermakova SP, Kang BS, Choi BY, Choi HS, Schuster TF, Ma WY, Bode AM and Dong Z: (-)-Epigallocatechin gallate overcomes resistance to etoposide-induced cell death by targeting the molecular chaperone glucose-regulated protein 78 . Cancer Res 66: 9260-9269, 2006.

32. Aggarwal BB, Kumar A and Bharti AC: Anticancer potential of curcumin: preclinical and clinical studies. Anticancer Res 23: 363-398, 2003

33. Li L, Aggarwal BB, Shishodia S, Abbruzzese J and Kurzrock R: Nuclear factor- $\kappa \mathrm{B}$ and $\mathrm{I} \kappa \mathrm{B}$ kinase are constitutively active in human pancreatic cells, and their down-regulation by curcumin (diferuloylmethane) is associated with the suppression of proliferation and the induction of apoptosis. Cancer 101: 2351-2362, 2004.

34. Pal S, Bhattacharyya S, Choudhuri T, Datta GK, Das T and Sa G: Amelioration of immune cell number depletion and potentiation of depressed detoxification system of tumor-bearing mice by curcumin. Cancer Detec Prev 29: 470-478, 2005.
35. Tharakan ST, Inamoto T, Sung B, Aggarwal BB and Kamat AM: Curcumin potentiates the antitumor effects of gemcitabine in an orthotopic model of human bladder cancer through suppression of proliferative and angiogenic biomarkers. Biochem Pharmacol 79: 218-228, 2010.

36. Dhillon N, Aggarwal BB, Newman RA, Wolff RA Kunnumakkara AB, Abbruzzese JL, Ng CS, Badmaev V and Kurzrock R: Phase II trial of curcumin in patients with advanced pancreatic cancer. Clin Cancer Res 14: 4491-4499, 2008.

37. Vadhan-Raj S, Weber D, Giralt S, Alexaman R, Thomas S, Zhou X, et al: Curcumin downregulates NF- $\kappa \mathrm{B}$ and related genes in patients with multiple myeloma. Results of a phase 1/2 study. Blood 110: 1177, 2007.

38. Brenner H, Gondos A and Pulte D: Recent trends in long-term survival of patients with chronic myelocytic leukemia: disclosing the impact of advances in therapy on the population level. Haematologica 93: 1544-1549, 2008. 